\title{
Analysis on the Development of New Chinese Costume Innovation Based on Popularization
}

\author{
Mengxin. ${ }^{1, a *}$, XiaoPing $^{2, \mathrm{~b}}$ \\ ${ }^{1}$ Clothing and apparel design,Shenyang Aerospace University,ShenYang,LiaoNing \\ ${ }^{2}$ Clothing and apparel design,Shenyang Aerospace University,ShenYang,LiaoNing
}

\begin{abstract}
The rise of new Chinese costumes reflects national cultural confidence. In response to how to quickly develop a questionnaire in the new Chinese costume market, it is designed and innovative through the public's data analysis of new Chinese costumes, color, fabrics, and patterns, through the innovation, color innovation, fabric innovation of new Chinese costumes. The newness of the texture innovation promotes its development and analyzes the development of good apparel brand marketing strategies. Combined with the advantages of integration innovation and development, broaden the new Chinese costume market, and in the development of the new Chinese costume market, inherit the traditional Chinese tradition culture.
\end{abstract}

\section{Foreword}

Economic globalization has accelerated the development of the fashion world. It brings huge opportunities and challenges for the clothing market. The high economic level has made people's basic functions for clothing demand, but higher levels to excavate the extraction of clothing. Demand, including apparel decoration aesthetics, costume multi-functionality. Modern local costumes have caused local cultural losses due to Western cultural impact, in recent years, in recent years, London Fashion Week, New York Fashion Week, Paris Fashion Week, Milan Fashion Week, China International Fashion Zhouxiu has experienced Chinese elements Apparel, in order to protect and promote Chinese traditional costume culture, local apparel designers began to pay attention to local costume culture, with a strong Chinese traditional cultural heritage, and the new Chinese costume market gradually opened, due to new Chinese costumes There is a certain limitations, this paper will be studied from the design innovation and marketing strategy of the apparel body.

\section{Development status of new Chinese costumes}

\section{1 new Chinese costume culture connotation}

As a carrier, clothing carries the profound cultural heritage and foundation of the nation. Among them, the symbols with national characteristics, such as modeling structure, patterns and so on, are concentrated in the traditional clothing, which makes the cultural symbols

\footnotetext{
*aEmail:mengxin0318@163.com

bEmail:1679250147@qq.com
}

carried by them more symbolic. [1] New Chinese clothing, as an inclusive product of the new era, is not limited to the integration of ancient Chinese culture and modern Chinese culture, but also reflected in the intersection of oriental culture and western culture. At the APEC summit in November 2014, Chu Yan, a local fashion designer, designed a series of clothes for leaders of 21 economies and their spouses, which was named "New China suit". The leader's clothing series is based on Chinese traditional culture, and the clothing design integrates a large number of traditional elements, which incisively and vividly embodies the clothing connotation of clothing culture. As a diplomatic etiquette dress, 'New Chinese suit' draws lessons from the design idea of Zhongshan suit, its root is' middle', soul is' etiquette', shape is' new', cherish tradition and are open and compatible [2]. New Chinese clothing, based on Chinese traditional culture, combined with modern fashion aesthetics, is a new form of clothing that is in line with the international trend, meets the aesthetic needs of the modern public and has social functions.

\section{2 the present situation of the development of new Chinese style clothing}

Since the 'new Chinese clothing' was really defined, the upsurge of new Chinese clothing, local clothing designers began to pay attention to the local culture, re-examine and excavate the design and application of Chinese elements in clothing, the new Chinese clothing market gradually opened. The Blue Book on the Development of China's Fashion Industry 2018 points out that China has entered the second echelon of the development of the world fashion industry, and the brands of clothing designed, developed and produced 
independently by China have occupied a leading position in the domestic market.[3] New Chinese clothing brands are also rising rapidly. The author counted the release times of Chinese elements into design in CFW shows from 2015 to 2020. There were 3 shows about the integration of Chinese elements into design in 2015, 14 in 2016, 19 in 2017, 24 in 2018, 29 in 2019 and 53 in 2020. The show with the combination of Chinese elements and clothing is on the rise as a whole. It shows that more and more designers pay more attention to local culture, and the development of Chinese clothing shows a good trend.

\section{3 combine the popular new Chinese style clothing design innovation}

With the enhancement of people's aesthetic concept and green consciousness, the demand for functional extension of clothing is strongly required to develop through innovation. Design innovation is a strong supporting point for clothing development. Whether the new Chinese style clothing can meet the individual and aesthetic needs of the public, it is necessary to optimize the quality and quantity of the new Chinese style clothing, enhance the design sense of the new Chinese style clothing, and promote the development of the new Chinese style clothing through innovative design. The development of new Chinese-style clothing should carry out innovative design to meet the needs of popularity, avoid flattening and homogenization of products, and adjust the proportion of design elements to make clothing more coordinated in vision and function. This time through the questionnaire star released the network questionnaire survey, through understanding and analyzing the public tendency, carry on the effective innovative design, form the theoretical support of the new Chinese clothing innovative design. This survey received 120 valid questionnaires, including personal information, new Chinese style clothing design factors, acceptance of new Chinese style clothing, purchase channels, purchase factors and so on.

\subsection{Modeling innovation based on popularization}

The ancient clothing used plane cutting, which did not emphasize the aesthetic feeling of the human body curve, such as the popular clothes in the Song Dynasty, the large-sleeved clothes with large sleeves, the narrow-sleeved clothes with long sleeves, and the casual clothes with narrow sleeves and short sleeves, most of which were shaped in one piece, and the inclusiveness was not strong. Modern aesthetic is fashionable, from the clothing style, structure, craftsmanship, as well as whether the travel is convenient or not, by Table 1. For the selection of the new Chinese clothing profile type, $66.67 \%$ choose the optimized minimalist type, $45 \%$ choose the multi-level heavy type, and $18.33 \%$ choose the structural retro type, which shows that the public is more inclined to optimize the minimalist new Chinese clothing profile, and the styling design is considered to be complicated and simple. the clothing profile should not be exaggerated, the clothing structure should be optimized, the simplicity of the overall outline of the clothing body should be emphasized, and the accumulation of complicated elements should be avoided. It can be transformed and innovated from the shape of the collar and placket of traditional clothing, but it can not be separated from the category of shape, and the innovation in details adds the Chinese charm of clothing so that the appearance of clothing is extremely simplified and the content of clothing is rich and full.

Table 1. The result of the investigation on the profile of New Chinese style Garment

\begin{tabular}{ccc}
\hline Options & $\begin{array}{c}\text { Number of } \\
\text { persons }\end{array}$ & Proportion \\
\hline $\begin{array}{c}\text { Optimized minimalist } \\
\text { Multi-level and } \\
\text { heavy-duty }\end{array}$ & 80 & $66.67 \%$ \\
Structural retro type & 18 & $45 \%$ \\
\hline
\end{tabular}

\subsection{Color Innovation based on Popularization}

As an important part of clothing design, color is the first element to convey the main connotation of clothing through the visual path, and it also determines the clothing style in the design. With the enhancement of consumers' fashion concepts, color changes will also affect consumers' purchase choices. From Table 3, the selection of color types of new Chinese clothing, 10.83\% choose colorful type, $72.5 \%$ choose fresh and light elegant type, $16.67 \%$ choose classical thick type, the public is more inclined to fresh and light elegant color, this type of color must be low purity and low brightness, can show that the color is soft and quiet, in the new Chinese clothing color innovation design, you can choose the popular color in the season. You can also seek color inspiration from contemporary paintings and extract colors corresponding to clothing style for fusion design. Colors with high saturation can be designed by reducing color purity and lightness, or by collocating colors of the same color system as a whole. the color with high lightness purity is used inside, and the color purity and lightness are reduced in turn from the inside to the outside, so that the overall color is in the same color system, and the comprehensive color is bright and dark to form a visually fresh and elegant color.

Table 2. The result of the investigation on the Color types of New Chinese style clothing

\begin{tabular}{ccc}
\hline Options & $\begin{array}{c}\text { Number of } \\
\text { persons }\end{array}$ & Proportion \\
\hline Colorful type & 13 & $10.83 \%$ \\
$\begin{array}{c}\text { Fresh and light } \\
\text { styling } \\
\begin{array}{c}\text { Classical thick } \\
\text { type }\end{array}\end{array}$ & 87 & $72.5 \%$ \\
\hline
\end{tabular}




\section{3 fabric Innovation based on Popularization}

Fabric is the most direct experience for consumers. The comfort, quality and functionality of clothing can be displayed through clothing fabric. Fabric innovation is the core of competition among clothing enterprises. For example, the HEATTECH series, AIRISM series, DRY-EX series and UV sunscreen series launched by Uniqlo all change the performance of the fabric and make the fabric warm in winter and cool in summer. Fabric innovation has become one of the important reasons for the sustainable development of Uniqlo. From Table 4, 59.17\% choose cotton and linen, $67.5 \%$ choose silk, $19.17 \%$ choose wool, $21.67 \%$ choose blended fabric, $16.67 \%$ choose chemical fiber, $8.33 \%$ choose other fabrics. Volkswagen chooses new Chinese-style clothing made of cotton, linen and silk fabrics, which fully shows that modern consumers pay attention to the comfort and functionality of natural fabrics. With the enhancement of people's concept of environmental protection, new Chinese clothing fabrics can use traditional natural fiber fabrics and new environmentally friendly recycled fiber fabrics, such as bamboo fiber, soybean fiber, organic cotton, flax, silk and other fabrics with good performance. analyze the advantages and characteristics of the fabric, extend the performance of the fabric, and combine the functions of the fabric and fabric by means of modern science and technology. Form a new Chinese clothing fabric with beauty, comfort, environmental protection and sustainability.

Table 3. Results of investigation on the material of New Chinese-style fabric

\begin{tabular}{ccc}
\hline Options & $\begin{array}{c}\text { Number of } \\
\text { persons }\end{array}$ & Proportion \\
\hline Cotton and linen & 71 & $59.17 \%$ \\
Silk & 81 & $67.5 \%$ \\
Wool & 23 & $19.17 \%$ \\
Blended spinning & 26 & $21.67 \%$ \\
Chemical fiber & 20 & $16.67 \%$ \\
Other & 10 & $8.33 \%$ \\
\hline
\end{tabular}

\section{4 pattern Innovation based on Popularization}

Pattern pattern is also an important element of clothing design, and pattern pattern plays a strong decorative role in clothing design. From Table 5, the public's choice of new Chinese clothing pattern types: $56.67 \%$ choose to inherit the national cultural connotation type, 9.17\% choose the abstract concept creation, $10.83 \%$ choose the concrete realistic creation type, $23.33 \%$ choose the trendy culture type. the public is more inclined to inherit the national cultural connotation and the pattern type of the trendy culture. based on the popular tendency, there are two ways to innovate the new Chinese pattern. Path one: to maintain the innovative design of the meaning of traditional patterns, the elements of the original patterns can not be lost. Path 2: traditional patterns and trendy cultural elements combined with innovative design, the traditional pattern design into trendy cultural elements.
These two kinds of innovation paths can apply the law of formal beauty to carry out innovative design, and only by using the methods of reorganization, replication, deformation and displacement to innovate patterns can they present innovative patterns with new ideas, and the overall form of patterns will change and the moral meaning will remain unchanged. Integration and innovation with the trendy culture not only keeps the national characteristics, but also adds the interest of the patterns at the same time.

Table 4. results of investigation on pattern types of New Chinese style clothing

\begin{tabular}{ccc}
\hline Options & $\begin{array}{c}\text { Number of } \\
\text { persons }\end{array}$ & Proportion \\
\hline $\begin{array}{c}\text { Inherit the } \\
\text { connotation of } \\
\text { national culture }\end{array}$ & 68 & $56.67 \%$ \\
$\begin{array}{c}\text { Abstract concept } \\
\text { creation }\end{array}$ & 11 & $9.17 \%$ \\
$\begin{array}{c}\text { Concrete realistic } \\
\text { creation }\end{array}$ & 13 & $10.83 \%$ \\
Trendy culture & 28 & $23.33 \%$ \\
\hline
\end{tabular}

\section{New Chinese clothing Marketing Strategy based on Popularization}

The long-term development of the new Chinese clothing market depends on the objective demand of popularization, grasps the subjective consumption consciousness, is good at using network tools to vigorously promote, quickly capture the needs of consumers, and clearly aim at the law of market development. accurate production to cater to the market strategy, from design to production, from production to output, all-round implementation of characteristic strategies.

\section{1 expand multiple sales channels}

The rapid development of information technology has diversified clothing sales channels, and the development of a variety of software has met the shopping needs of consumers. with the popularization of social platforms such as Douyin, Weibo and Xiaohongshu, we can carry out "carrying goods" in the form of live broadcasting. increase the exposure of goods, open Subscription account, to facilitate the spread of brand culture and consumers to buy goods. Launch online and offline joint activities to provide a comprehensive shopping experience, offline need to optimize store configuration, improve service quality, accumulate passenger flow to win the second buyback. Online, increasing advertising efforts on online channels is conducive to the spread of clothing brand culture, fully promote the docking with the target market, use platform extension for marketing, based on the public's multi-frequency use of new media social platforms, use the network platform to enhance interaction and communication, improve the advertising investment of new Chinese clothing brands, put clothing 
links, and carry out multi-channel sales.

\subsection{Joint name of cross-border and brand}

The mode of cross-border cooperation can be used to inject new elements, so as to achieve the purpose of expansion, transformation, promotion, promotion and interaction of independent designer brands. Typical forms of cross-border cooperation between clothing brands of different audiences, cross-border cooperation with art practitioners and cross-border cooperation of brands in other fields [4], this innovative model can construct hierarchical perception and give new forms of vision and experience. Brand image spatial structure double-layer construction, injection of double charm, cultural blending to enhance the value of the brand. Art communicates with each other, and cross-border cooperation in their respective fields has become a popular marketing means at present, showing a good effect on brand awareness and brand promotion. The clothing industry can cooperate with art, architecture, animation, film, food and other fields to create development opportunities. Cross-border cooperation is an important path for the development of new Chinese clothing brands. Cooperate with trendy brands, artists and well-known designers to integrate old and new elements, enhance the sense of clothing design, and bring new and unique new Chinese clothing products to the market. Cross-border cooperation plays a positive role in the promotion, expansion and value promotion of new Chinese clothing.

\section{Conclusion}

The development of new Chinese style clothing should be promoted by innovation, the innovation of clothing design should be combined with marketing, design inside, marketing outside, complement each other, design innovation makes clothing valuable, innovative marketing strategy broadens the use value of clothing, innovation injects vitality into the development of new Chinese clothing market, the development of new Chinese clothing wants to be universal, it needs to rely on consumers and resonate with market value. To build innovative forms based on the masses and form efficient and convenient ways of communication, new Chinese clothing brands need to establish a systematic system and mechanism, actively explore the laws of market development, and accurately locate consumers. For consumers and designers to build a communication platform from the outside to the inside and from the inside to the outside, to explore the innovative development of new Chinese clothing is conducive to the development of Chinese clothing brands to enrich the theoretical basis, at the same time. It also has a certain guiding significance for the inheritance and design innovation of Chinese traditional clothing culture.

\section{References}

1. Shi, W.F., Wu, Z.M., (2018) The Design Innovation of "New Chinese clothing" based on the inheritance of Garment Culture., 3(06): 523-528.

2. Liu, Y.F., (2016)"New Chinese suit" shows the dominant sign of cultural self-confidence.J. Beijing observation.,74-75.

3. Chen, W.H.(2018)Blue Book of Chinese Fashion Industry. Economic Management Press, Beijing.

4. Sun,Y., (2013)Research on the Cross-border Cooperation Mode of clothing Brands.J. Silk.,50(11): 75-79. 